\title{
LUAS OPTIMUM PETAK UKUR UNTUK HUTAN TANAMAN KAYU PUTIH DI KESATUAN PENGELOLAAN HUTAN YOGYAKARTA
}

\author{
(Optimum Size of Sampling Plot for Cajuput Plantation \\ at Forest Management Unit Yogyakarta)
}

\author{
Budi Mulyana $^{1 *}, \operatorname{Rohman}^{1} \&$ Wahyu Wardhana ${ }^{1}$ \\ ${ }^{1}$ Departemen Manajemen Hutan, Fakultas Kehutanan, Universitas Gadjah Mada, \\ Jl Agro No.1 Bulaksumur Yogyakarta, 55281 \\ Email : budimulyana@ugm.ac.id
}

\begin{abstract}
Utilization of non-timber forest products, especially cajuput plants in Indonesia needs to be optimalized. The management of cajuput plantations should be supported with data and information toward sustainable management. The plot size to estimate the potential of cajuput leaves has not been determined. Therefore, the determination of the optimal plot size which be used to invent cajuput plantations was carried out in this study. Cajuput stands having good degree of normality were used in this study. Several sample plots size of $20 \times 20 \mathrm{~m}, 30 \times 30 \mathrm{~m}, 40 \times 40 \mathrm{~m}, 50 \times$ $50 \mathrm{~m}, 60 \times 60 \mathrm{~m}, 70 \times 70 \mathrm{~m}, 80 \times 80 \mathrm{~m}, 90 \times 90 \mathrm{~m}$, and standard plot (control) $100 \times 100 \mathrm{~m}$ were used in this study. Parameters measured were number of tree $(\mathrm{n} / \mathrm{ha})$ and the biomass of cajuput leaves-twig $(\mathrm{Kg} / \mathrm{ha})$. Data were analyzed by using $t$-student test to determine the difference of mean value between sample sample plot and control plot. The analysis was also done by calculating the precision of each sample plot. The result showed that the estimated value of number of tree (n/ ha) of the $20 \mathrm{~m} \times 20 \mathrm{~m}$ plot size was not significantly different with the control plot size of $100 \mathrm{~m} \times 100 \mathrm{~m}$. Estimation of leaves-twigs biomass of cajuput with plot size of $20 \mathrm{~m} \times 20 \mathrm{~m}$ plot was also not significantly different with the result of measurement of leaves-twigs biomass of cajuput in control plot $100 \mathrm{~m} \times 100 \mathrm{~m}$. It can be summarized that the optimum plot size that can be used in the study site is $20 \mathrm{~m} \times 20 \mathrm{~m}$.
\end{abstract}

Keywords: Inventory, plot size, cajuput, biomass, stand density

\begin{abstract}
ABSTRAK
Pemanfaatan hasil hutan bukan kayu khususnya tanaman kayu putih di Indonesia masih perlu dioptimalkan. Data dan informasi mengenai kondisi tegakan sangat diperlukan untuk pengelolaan secara lestari. Pendekatan sampling plot dalam menduga potensi daun kayu putih belum memiliki ukuran luas yang baku. Penelitian bertujuan untuk mengetahui luas petak ukur optimal yang dapat digunakan di hutan tanaman kayu putih. Bahan penelitian adalah tegakan tanaman kayu putih yang memiliki derajat kenormalan baik. Metode penelitian menggunakan petak ukur sampel berbentuk bujur sangkar dengan ukuran 20 × $20 \mathrm{~m}, 30$ × $30 \mathrm{~m}, 40$ x $40 \mathrm{~m}, 50$ x $50 \mathrm{~m}, 60$ × $60 \mathrm{~m}, 70$ x $70 \mathrm{~m}, 80$ × $80 \mathrm{~m}, 90 \times 90 \mathrm{~m}$, dan petak ukur standar (kontrol) 100 x $100 \mathrm{~m}$. Parameter yang diukur adalah kerapatan tegakan (n/ha) serta biomassa daun-ranting kayu putih $(\mathrm{kg} / \mathrm{ha})$. Data dianalisis menggunakan uji t-student untuk mengetahui perbedaan nilai rata-rata antara petak ukur sampel dengan petak ukur kontrol. Analisis juga dilakukan dengan menghitung kecermatan dari setiap petak ukur sampel. Hasil penelitian menunjukkan bahwa nilai dugaan kerapatan tegakan (n/ha) dari luas petak ukur $20 \mathrm{~m}$ x $20 \mathrm{~m}$ tidak berbeda nyata dengan luas petak ukur kontrol $100 \mathrm{~m}$ x $100 \mathrm{~m}$. Pendugaan biomassa daun-ranting kayu putih dengan luas petak ukur $20 \mathrm{~m}$ x $20 \mathrm{~m}$ juga tidak berbeda nyata dengan hasil pengukuran biomassa daun-ranting kayu putih di petak ukur kontrol $100 \mathrm{~m}$ x $100 \mathrm{~m}$. Dengan demikian, luas optimum petak ukur yang dapat digunakan di lokasi penelitian adalah berukuran $20 \mathrm{~m}$ x $20 \mathrm{~m}$.
\end{abstract}

Kata kunci: Inventarisasi, petak ukur, kayu putih, biomasa, kerapatan tegakan

\section{PENDAHULUAN}

Hutan memberikan banyak manfaat bagi masyarakat dalam bentuk barang (kayu dan non-kayu) serta jasa lingkungan. 
Pengelolaan hutan pada saat ini masih berorientasi pada pemanfaatan kayu sebagai sumber utama hasil hutan. Produksi kayu bulat di Indonesia dalam kurun waktu tahun 2007-2011 meningkat dari 32,2 juta $\mathrm{m}^{3}$ menjadi 47,4 juta $\mathrm{m}^{3} \quad$ (Kementerian Kehutanan, 2012). Di lain pihak, hasil hutan bukan kayu (HHBK) yang berasal dari hutan belum dimanfaatkan dengan baik.

HHBK memiliki potensi yang sangat besar di Indonesia. Pemerintah telah menetapkan HHBK yang dapat dimanfaatkan di Indonesia melalui Peraturan Menteri Kehutanan Nomor: P.35/Menhut-II/2007 tentang Hasil Hutan Bukan Kayu. Pengertian HHBK berdasarkan Peraturan Menteri tersebut adalah hasil hutan hayati baik nabati maupun hewani beserta produk turunan dan budidaya kecuali kayu yang berasal dari hutan. HHBK tersebut dikelompokkan menjadi 494 jenis dari tumbuhan dan 63 jenis dari satwa.

HHBK kategori tumbuhan obat terdiri dari 157 jenis dan sudah banyak dimanfaatkan oleh masyarakat. Kayu putih merupakan salah satu hasil dari tumbuhan obat yang sering digunakan di masyarakat. Hutan kayu putih juga menopang pendapatan masyarakat di sekitar kawasan hutan kayu putih. Masyarakat di sekitar hutan kayu putih Kesatuan Pengelolaan Hutan (KPH) Yogyakarta memanfaatkan lahan di bawah tegakan untuk kegiatan budidaya pertanian (Dinas Kehutanan dan Perkebunan DIY, 2014) sedangkan masyarakat di Kabupaten Seram Bagian Barat memanfaatkan hutan kayu putih dengan cara penyulingan daun kayu putih untuk memperoleh minyak kayu putih sebagai pendapatan utama masyarakat (Salaka, Nugroho, \& Nurrochmat, 2012).

Tanaman kayu putih telah dibudidayakan di Indonesia. Hutan tanaman kayu putih di Indonesia tersebar di Pulau
Jawa, Kepulauan Maluku, dan Nusa Tenggara (Baskorowati, Susanto, Prastyono, Kartikawati, \& Rimbawanto, 2012). Hutan tanaman kayu putih di Pulau Jawa dikembangkan oleh Perhutani dan KPH Model Yogyakarta. Perhutani mengelola tanaman kayu putih di Jawa Barat, Jawa Tengah, dan Jawa Timur dengan luas 22.759 ha (Perhutani, 2012), sedangkan KPH Model Yogyakarta sudah mengelola tanaman kayu putih di Provinsi DIY dengan luas areal 4.508,8 ha (Dinas Kehutanan dan Perkebunan DIY, 2014). Selain di Pulau Jawa dan Maluku, tanaman kayu putih juga telah dikembangkan di lahan bekas tambang batubara di Sumatera Selatan seluas 1.799 ha (Kodir, Hartono, Haeruman, \& Mansur, 2017). Tanaman kayu putih juga akan dikembangakan di Provinsi Nusa Tenggara Barat oleh pihak swasta dengan luas 4.500 ha (Badan Penelitian Pengembangan dan Inovasi Kementerian Lingkungan Hidup dan Kehutanan, 2016). Namun, produksi daun kayu putih secara nasional, 97,88\% berasal dari hutan tanaman kayu putih di Pulau Jawa (Badan Pusat Statistik, 2016).

Data dan informasi untuk mendukung pengelolaan hutan tanaman kayu putih masih terbatas. Metode inventarisasi HHBK masih belum memiliki standar baku, baik dalam penentuan sampel (metode sampling, luas petak ukur, dan intensitas sampling) maupun data yang dikumpulkan. Vanclay (1994) membagi kegiatan inventarisasi hutan menjadi inventarisasi statis (static inventory) untuk memperoleh data dan informasi dalam kurun waktu tertentu dengan menggunakan petak ukur sementara (PUS) dan inventarisasi dinamis (dynamic inventory) dilakukan terus menerus dilakukan dalam jangka waktu yang panjang dengan menggunakan petak ukur permanen (PUP). 
Petak ukur yang digunakan selama ini di hutan tanaman kayu putih dalam rangka penelitian maupun inventarisasi periodik masih berbentuk petak ukur sementara. Pembuatan petak ukur permanen oleh pengelola kawasan (Perhutani atau KPH Yogyakarta) di hutan tanaman kayu putih masih jarang dilakukan. Pedoman atau penelitian mengenai pembuatan petak ukur di hutan kayu putih belum diketahui, sehingga luas optimal dalam pembuatan petak ukur mengacu pada hasil penelitian Harbagung \& Imanuddin (2009) yang telah menerapkannya pada hutan jati, serta Utomo, Suhendang, Syafii, \& Simangunsong (2012) dan Utomo (2012) yang telah menerapkannya pada hutan tanaman kayu putih di Perhutani.

\section{BAHAN DAN METODE}

\section{A. Lokasi dan Waktu Penelitian}

Penelitian dilakukan pada petak 31

RPH Gelaran, BDH Karangmojo, KPH Yogyakarta. Penelitian dilaksanakan selama 5 bulan dari April sampai dengan Agustus 2017.
Tanaman kayu putih yang berada di petak 31 ditanam pada tahun 1970-an, 1980-an, 1990-an, serta pengayaan di tahun 2012.

\section{B. Alat dan Bahan}

Alat yang digunakan dalam penelitian ini adalah kompas, GPS, timbangan digital, pita meter. Bahan penelitian adalah tanaman kayu putih yang berada di petak $31 \mathrm{RPH}$ Gelaran, BDH Karangmojo, KPH Yogyakarta.

\section{Metode Pengumpulan Data}

Data yang dihitung adalah jumlah pohon dan biomassa daun-ranting pada berbagai ukuran petak ukur. Bentuk dan pola petak ukur yang dibuat mengikuti pada penelitian Harbagung \& Imanuddin (2009) yang membagi petak ukur kedalam ukuran 20 x $20 \mathrm{~m}, 30$ x $30 \mathrm{~m}, 40$ x $40 \mathrm{~m}, 50$ x $50 \mathrm{~m}, 60$ x $60 \mathrm{~m}, 70 \times 70 \mathrm{~m}, 80 \times 80 \mathrm{~m}$, dan 90 x $90 \mathrm{~m}$ (Gambar 1). Lokasi penelitian di petak 31 seluas 74,6 ha dibagi menjadi 74 petak ukur dengan luas 1 ha. Petak ukur yang menjadi sampel penelitian berjumlah 9 petak yang dipilih secara acak.

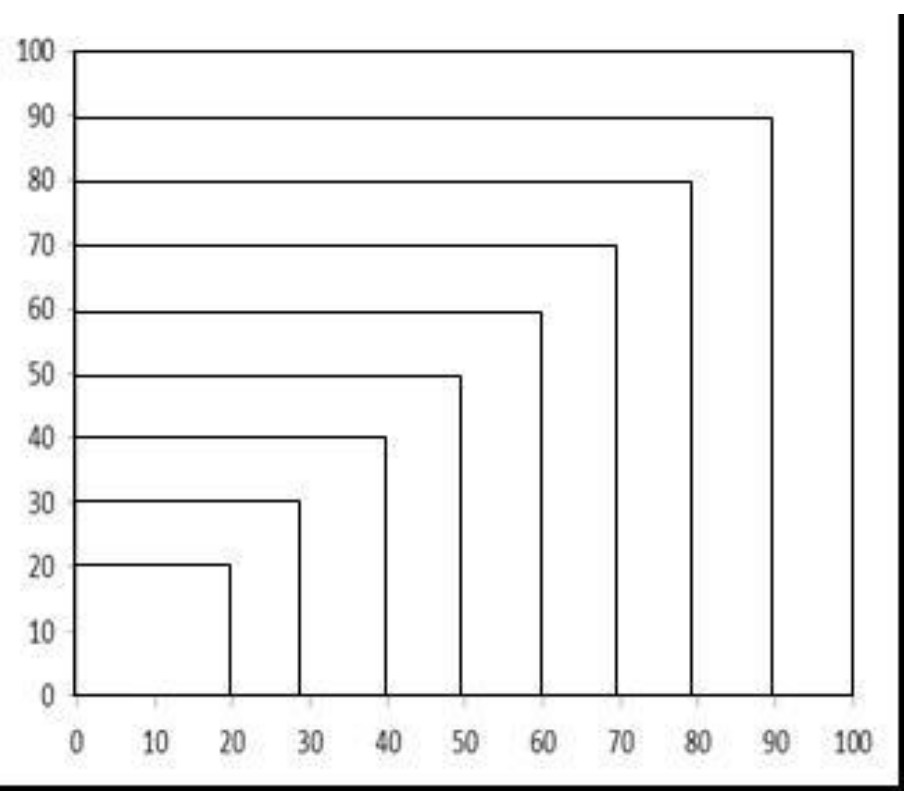

Gambar 1. Pola berbagai ukuran petak ukur sampel

Figure 1. Patterns of various sizes of sample size plots 


\section{Jumlah pohon}

Jumlah pohon pada setiap petak ukur yang menjadi sampel penelitian diperoleh dengan cara menghitung semua tanaman kayu putih yang masuk ke dalam setiap bentuk petak ukur. Satuan jumlah pohon yang digunakan dalam analisa data adalah jumlah pohon untuk setiap luas petak ukur $\left(\mathrm{n} / \mathrm{m}^{2}\right)$, sehingga nilai yang diperoleh dari setiap bentuk ukuran petak ukur dikonversi ke dalam satuan pohon/ha (n/ha).

$$
I p_{\text {plot }}=\frac{\sum_{i=1}^{n} P_{i}}{L}
$$

\section{Keterangan:}

$\mathrm{Jp}_{\text {plot }}$ : Jumlah pohon di petak ukur

$\mathrm{P}_{\mathrm{i}} \quad$ : Pohon ke $i$

L : Luas petak ukur dalam satuan hektar

\section{Biomassa daun-ranting kayu putih}

Biomasa daun-ranting kayu putih diperoleh dengan cara memangkas semua daun dan ranting yang terdapat di setiap bentuk petak ukur. Ranting kayu putih yang masuk dalam penimbangan maksimum berdiameter $0,5 \mathrm{~cm}$. Satuan untuk biomasa kayu putih yang digunakan dalam analisa data adalah $\mathrm{Kg} / \mathrm{ha}$, sehingga nilai yang diperoleh dari setiap pohon pada masing-masing bentuk petak ukur dijumlahkan terlebih dahulu, kemudian dikonversi kedalam satuan $\mathrm{Kg} / \mathrm{ha}$.

$$
B_{\text {plot }}=\frac{\sum_{i=1}^{n} B_{i}}{L}
$$

Keterangan:

$\mathrm{B}_{\text {plot }}:$ Biomassa daun-ranting kayu putih di petak ukur

$\mathrm{B}_{\mathrm{i}} \quad$ : Biomassa daun-ranting kayu putih dari pohon ke $i$

L : Luas petak ukur petak ukur dalam satuan hektar

\section{Analisis Data}

Data yang diperoleh dari hasil penelitian dianalisis secara statistik dengan menggunakan uji t-student berpasangan. Pengujian dilakukan antara masing-masing ukuran petak ukur dengan petak ukur kontrol (100 x $100 \mathrm{~m})$. Pengujian nilai rata-rata dua sampel berpasangan dengan menggunakan uji t. Hipotesis penelitian adalah sebagai berikut:

$\mathrm{H}_{0} \quad: \mu_{1}=\mu_{2}$ (nilai rata-rata dari ukuran plot tidak berbeda nyata dengan nilai rata rata dari plot kontrol)

$\mathrm{H}_{1} \quad: \mu_{1} \neq \mu_{2}$ (nilai rata-rata dari ukuran plot berbeda nyata dengan nilai rata rata dari plot kontrol)

Perhitungan nilai kritis ( $\mathrm{t}_{\text {hitung }}$ ) dalam Sadono, Murdawa, Soeprijadi, \& Nawari (2016) adalah sebagai berikut:

$$
t_{\text {hitung }}=\frac{d}{S d / \sqrt{n}}
$$

Keterangan:

d : Nilai rata-rata

$\mathrm{Sd}$ : Standar deviasi

$\mathrm{n} \quad$ : Jjumlah sampel

Penarikan kesimpulan:

$\mathrm{H}_{0}$ diterima apabila $\mathrm{t}_{\text {hitung }}<\mathrm{t}_{\text {tabel }}$

$\mathrm{H}_{1}$ diterima apabila $\mathrm{t}_{\text {hitung }}>\mathrm{t}_{\text {tabel }}$

Kecermatan sampel relatif berdasarkan (Simon, 2010) menggunakan persamaan sebagai berikut:

$$
P=\left(\frac{S_{\bar{x}}}{\bar{x}}\right) \times 100
$$

Keterangan:

$\mathrm{P} \quad$ : Kecermatan relatif

$S_{\bar{x}}:$ Standar eror

$\bar{x}$ : Harga rata-rata 


\section{HASIL DAN PEMBAHASAN}

\section{A. Kondisi Umum Lokasi Penelitian}

Penelitian dilaksanakan pada hutan tanaman kayu putih di petak 31, RPH Gelaran, BDH Karangmojo, KPH Yogyakarta. Pemilihan petak 31 didasarkan pada hasil inventarisasi sumber daya hutan yang dilaksanakan oleh KPH Yogyakarta pada tahun 2010. Hasil inventarisasi oleh KPH Yogyakarta pada tahun 2010 menunjukkan bahwa petak 31 memiliki derajat kenormalan paling baik dari semua tanaman kayu putih yang ada di KPH Yogyakarta.

Hasil pemetaan dengan foto udara, hutan tanaman kayu putih di petak $31 \mathrm{KPH}$ Model Yogyakarta termasuk dalam kategori homogen. Tanaman kayu putih di petak 31 yang homogen maka penempatan plot sampel untuk setiap kelas tanamanan kayu putih dapat dilakukan secara acak. Plot sampel masing-masing seluas 1 ha dan yang terpilih adalah plot sampel no. 35, 39, 42, 14, 23, 60, 9, 49, dan 56 (Gambar 2).

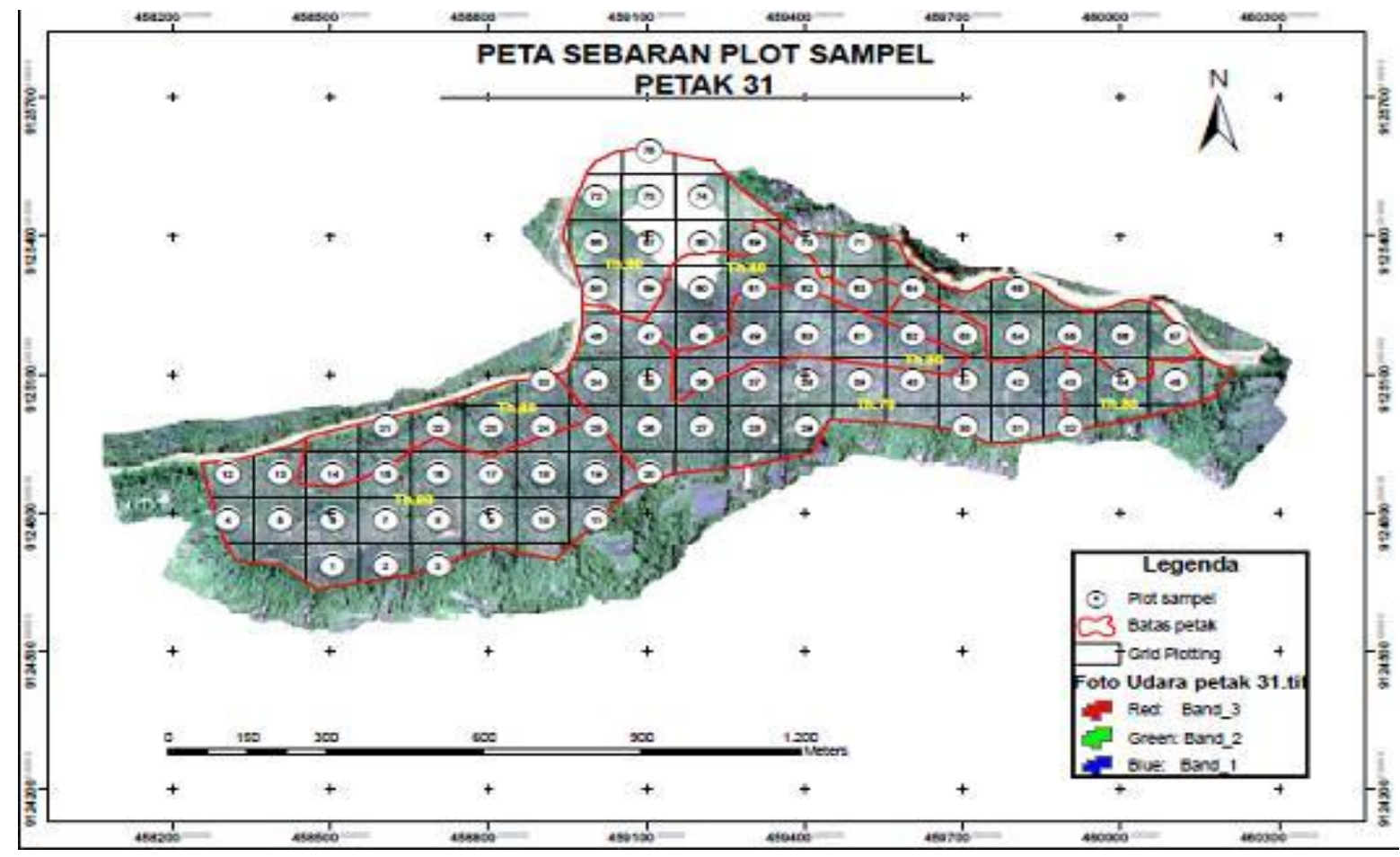

Gambar 2. Peta sebaran petak ukur sampel di lokasi penelitian Figure 2. Map of distribution of sample sample plots at research sites

Petak ukur sampel yang terpilih dengan luas 1 ha $(100 \mathrm{x} 100 \mathrm{~m})$ dibagi menjadi sub-petak ukur dengan ukuran $20 \mathrm{x}$ $20 \mathrm{~m}, 30 \times 30 \mathrm{~m}, 40 \times 40 \mathrm{~m}, 50 \times 50 \mathrm{~m}, 60 \times$ $60 \mathrm{~m}, 70 \times 70 \mathrm{~m}, 80 \times 80 \mathrm{~m}$, dan $90 \times 90 \mathrm{~m}$. Setiap tanaman kayu putih yang masuk dalam sub-petak ukur dihitung dan diukur jumlah pohon dan biomassa daun-ranting (Tabel 1). Nilai rata-rata jumlah pohon dan biomassa daun-ranting untuk setiap sub-petak ukur kemudian dibandingkan dengan nilai rata-rata jumlah pohon dan biomassa daun-ranting plot kontrol ukuran 100 x 100 m. 
Tabel. 1. Jumlah pohon dan biomassa daun-ranting

Table 1. Number of trees and biomass of leave-twigs

\begin{tabular}{llccccc}
\hline No & $\begin{array}{c}\text { Parameter } \\
\text { (parameters) }\end{array}$ & $\begin{array}{c}\text { Satuan } \\
\text { (unit) }\end{array}$ & $\begin{array}{c}\text { Minimal } \\
(\text { minimum })\end{array}$ & $\begin{array}{c}\text { Maksimal } \\
\text { (maximum) }\end{array}$ & $\begin{array}{c}\text { Rata-rata } \\
\text { (mean) }\end{array}$ & $\begin{array}{c}\text { Standar deviasi } \\
\text { (standard of } \\
\text { deviation) }\end{array}$ \\
\hline 1 & $\begin{array}{l}\text { Jumlah pohon } \\
\text { Biomassa } \\
\text { daun-ranting }\end{array}$ & $\mathrm{n} / \mathrm{ha}$ & 528,00 & $2.355,00$ & $1.052,00$ & 570,47 \\
& $\mathrm{Kg} / \mathrm{ha}$ & $1.225,16$ & $3.203,40$ & $1.999,00$ & 696,85 \\
\hline
\end{tabular}

Keterangan : Data diolah dari data primer

Remarks : Data processed from primary data

Lahan di petak 31 selain ditanami dengan tanaman kayu putih, dimanfaatkan juga oleh masyarakat sekitar hutan untuk tumpang sari. Tanaman yang dibudidayakan adalah kacang tanah, singkong, jagung, dan hijauan pakan ternak. Masyarakat yang memanfaatkan lahan di bawah tegakan kayu putih tergabung dalam Kelompok Tani Hutan $(\mathrm{KTH})$. Setiap anggota KTH rata-rata memperoleh lahan garapan seluas 0,1 ha.

\section{B. Luas Petak Ukur Optimal untuk Menduga Jumlah Pohon}

Jumlah pohon yang dihitung di 9 petak ukur sampel berjumlah 9.468 pohon. Setiap sub-petak ukur dihitung semua pohon yang masuk dalam petak ukur. Hasil penghitungan jumlah pohon pada setiap sub-petak ukur kemudian dikonversi kedalam satuan jumlah pohon untuk setiap hektar (Tabel 2.).

Tabel 2. Jumlah pohon pada petak ukur sampel Table 2. Number of trees for each sample plot size

\begin{tabular}{|c|c|c|c|c|c|c|c|c|c|}
\hline \multirow{2}{*}{$\begin{array}{c}\text { Luas petak }\left(\mathbf{m}^{2}\right) \\
(\text { plot size })\left(m^{2}\right)\end{array}$} & \multicolumn{9}{|c|}{$\begin{array}{l}\text { Jumlah pohon pada plot sampel (n/ha) } \\
\text { (number of trees on sample plot) }(\mathrm{n} / \mathrm{ha})\end{array}$} \\
\hline & 35 & 39 & 42 & 14 & 23 & 60 & 9 & 49 & 56 \\
\hline $20 \times 20$ & 1.525 & 1.175 & 975 & 850 & 200 & 425 & 825 & 475 & 2.400 \\
\hline $30 \times 30$ & 1.178 & 1.100 & 744 & 2.322 & 244 & 644 & 822 & 478 & 1.811 \\
\hline $40 \times 40$ & 1.081 & 1.006 & 738 & 2.938 & 313 & 631 & 1.525 & 675 & 1.406 \\
\hline $50 \times 50$ & 1.148 & 760 & 840 & 2.944 & 648 & 836 & 1.748 & 596 & 1.316 \\
\hline $60 \times 60$ & 1.233 & 608 & 883 & 2.789 & 536 & 775 & 1.489 & 681 & 986 \\
\hline $70 \times 70$ & 1.355 & 580 & 1.035 & 2.590 & 584 & 771 & 1.431 & 751 & 1.002 \\
\hline $80 \times 80$ & 1.330 & 536 & 903 & 2.598 & 619 & 748 & 1.428 & 716 & 963 \\
\hline $90 \times 90$ & 1.273 & 542 & 754 & 2.453 & 563 & 772 & 1.427 & 673 & 935 \\
\hline $100 \times 100$ & 1.241 & 528 & 1.009 & 2.355 & 591 & 775 & 1.404 & 650 & 915 \\
\hline
\end{tabular}

Keterangan: Data diolah dari data primer plot sampel yang terpilih adalah nomor 35, 39, 42, 14, 23, 60, 9 , 49, dan 56

Remarks : Data processed from primary data selected sample plots are number 35, 39, 42, 14, 23, 60, 9, 49, and 56

Jumlah pohon kayu putih di petak 31 berdasarkan hasil penghitungan langsung di lapangan menunjukkan nilai rata-rata sebesar 1.052 pohon/ha. Nilai tersebut berbeda dengan hasil inventarisasi yang dilaksanakan $\mathrm{KPH}$ Yogyakarta pada tahun 2010, dimana jumlah pohon pada petak 31 adalah 1.650 pohon/ha (Dinas Kehutanan dan Perkebunan DIY, 2014). 
Dalam kurun waktu 7 tahun, jumlah pohon di petak 31 berkurang rata-rata 85 pohon/ha/tahun.

Nilai dugaan jumlah pohon pada setiap sub-petak ukur dapat lebih besar atau lebih kecil dari petak ukur kontrol. Perbedaan nilai tersebut diduga oleh pola jarak tanam yang mulai tidak teratur atau penggunaan lahan untuk sarana transportasi/jalan angkutan di dalam lokasi penelitian. Pengamatan di lokasi penelitian, saat ini tanaman kayu putih yang ditanam sejak tahun 1974 jarak tanamnya mulai tidak beraturan. Selain itu, pemanfaatan lahan untuk jalan angkutan juga berdampak pada menurunnya jumlah tanaman. Pembukaan lahan untuk pembuatan jalan angkutan mengakibatkan pemangkasan tanaman sepanjang jalan angkutan.

Nilai rata-rata jumlah pohon pada setiap sub-petak ukur yang dibandingkan dengan nilai rata-rata jumlah pohon di petak ukur kontrol $(100 \times 100 \mathrm{~m})$ tidak berbeda nyata (Tabel 3.). Luas petak ukur yang dapat digunakan dalam menduga jumlah pohon di hutan tanaman kayu putih di lokasi penelitian adalah ukuran $20 \times 20 \mathrm{~m}$.

Tabel 3. Uji t-student berpasangan jumlah pohon untuk setiap ukuran petak ukur Table 3. Pair t-student test for number of trees in each plot size

\begin{tabular}{|c|c|c|c|c|}
\hline \multirow{2}{*}{$\begin{array}{c}\text { Luas petak ukur }\left(\mathrm{m}^{2}\right) \\
(\text { plot size })\left(\mathrm{m}^{2}\right)\end{array}$} & \multirow{2}{*}{$\mathbf{t}_{\text {hitung }}$} & \multicolumn{2}{|c|}{$\mathbf{t}_{\text {tabel }}$} & \multirow{2}{*}{$\begin{array}{c}\text { Kecermatan }(\%) \\
\text { (precision) }(\%)\end{array}$} \\
\hline & & 0,05 & 0,01 & \\
\hline $20 \times 20$ & $-0,309$ & 2,306 & 3,355 & 2,164 \\
\hline $30 \times 30$ & $-0,062$ & 2,306 & 3,355 & 1,978 \\
\hline $40 \times 40$ & 0,364 & 2,306 & 3,355 & 1,996 \\
\hline $50 \times 50$ & 0,609 & 2,306 & 3,355 & 1,792 \\
\hline $60 \times 60$ & 0,244 & 2,306 & 3,355 & 1,896 \\
\hline $70 \times 70$ & 0,334 & 2,306 & 3,355 & 1,675 \\
\hline $80 \times 80$ & 0,193 & 2,306 & 3,355 & 1,772 \\
\hline $90 \times 90$ & $-0,042$ & 2,306 & 3,355 & 1,809 \\
\hline
\end{tabular}

Keterangan : Data diolah dari data primer

Remarks : Data processed from primary

\section{Luas Petak Ukur Optimal Untuk Menduga Biomassa Daun-Ranting Kayu Putih}

Biomasa daun-ranting kayu putih diperoleh dengan melakukan pemangkasan pada setiap pohon, kemudian ditimbang. Ranting atau cabang yang masuk dalam kategori penimbangan adalah yang memiliki diameter kurang dari $0,5 \mathrm{~cm}$. Daun kayu putih (DKP) merupakan campuran antara daun kayu putih dengan ranting dan cabang yang memiliki diameter kurang dari $0,5 \mathrm{~cm}$ (Utomo et al., 2012). Hasil pengukuran biomasa daun-ranting kayu putih dapat disajikan pada tabel 4.

Biomassa daun-ranting kayu putih di lokasi penelitian berkisar antara $659-5.370$
$\mathrm{Kg} / \mathrm{ha} /$ panen. Panen daun kayu putih pada umumnya dilaksanakan setiap $9-12$ bulan. Setiap pohon kayu putih pada lokasi penelitian, rata-rata dapat menghasilkan biomassa daun-ranting seberat $1,99 \mathrm{Kg} /$ pohon/panen. Rata-rata biomassa daun-ranting kayu putih (Budiadi, Kanazawa, Ishii, Sabarnurdin, \& Suryanto, 2005) di Pehutani sebesar $2.800 \mathrm{Kg} / \mathrm{ha}$ dan beberapa plot ada yang menghasilkan biomasa sampai dengan 4.000 $\mathrm{Kg} / \mathrm{ha}$. Hasil daun kayu putih yang ditanam di lahan bekas tambang batu bara dapat menghasilkan $1 \mathrm{Kg} /$ pohon/panen (Kodir et al., 2017). Sedangkan rata-rata berat daun kayu putih dari jenis Asteromyrtus symphocarpa di Taman Nasional Wasur mencapai 2,03 Kg/pohon (Siarudin, Winara, Indrajaya, Junaidi, \& Widiyanto, 2013). 
Tabel 4. Biomassa daun-ranting kayu putih pada setiap ukuran petak ukur sampel Table 4. Biomass leave-twigs of cajuput for each sample plot size

\begin{tabular}{|c|c|c|c|c|c|c|c|c|c|}
\hline \multirow{2}{*}{$\begin{array}{c}\text { Luas petak } \\
\left(\mathbf{m}^{2}\right) \\
(\text { plot size })\left(m^{2}\right)\end{array}$} & \multicolumn{9}{|c|}{$\begin{array}{l}\text { Biomassa daun-ranting pada plot sampel }(\mathrm{Kg} / \mathrm{ha}) \\
\text { (biomass of leave-twigs on sample plot) }(\mathrm{Kg} / \mathrm{ha})\end{array}$} \\
\hline & 35 & 39 & 42 & 14 & 23 & 60 & 9 & 49 & 56 \\
\hline $20 \times 20$ & 5.231 & 2.173 & 3.826 & 2.088 & 659 & 705 & 690 & 793 & 7.123 \\
\hline $30 \times 30$ & 3.761 & 2.015 & 2.896 & 3.372 & 897 & 1.331 & 1.059 & 884 & 5.370 \\
\hline $40 \times 40$ & 3.422 & 2.062 & 2.981 & 3.293 & 927 & 1.193 & 1.393 & 1.507 & 4.004 \\
\hline $50 \times 50$ & 3.040 & 1.727 & 3.025 & 3.185 & 1.133 & 1.974 & 1.941 & 1.398 & 3.615 \\
\hline $60 \times 60$ & 2.764 & 1.414 & 2.833 & 3.176 & 1.359 & 1.692 & 1.758 & 1.354 & 2.823 \\
\hline $70 \times 70$ & 2.651 & 1.293 & 3.137 & 2.918 & 1.416 & 1.629 & 1.778 & 1.429 & 2.809 \\
\hline $80 \times 80$ & 2.460 & 1.193 & 2.769 & 2.842 & 1.521 & 1.568 & 1.801 & 1.318 & 2.688 \\
\hline $90 \times 90$ & 2.289 & 1.283 & 2.307 & 2.643 & 1.342 & 1.668 & 1.816 & 1.211 & 2.605 \\
\hline 100100 & 2.133 & 1.298 & 3.203 & 2.708 & 1.368 & 1.693 & 1.816 & 1.225 & 2.546 \\
\hline
\end{tabular}

Keterangan: Data diolah dari data primer plot sampel yang terpilih adalah nomor 35, 39, 42, 14, 23, 60, 9 , 49, dan 56

Remarks : Data processed from primary data Selected sample plots are number 35, 39, 42, 14, 23, 60, 9 , 49 , and 56

Nilai rata-rata biomassa daun-ranting kayu putih pada petak ukur kontrol dibandingkan dengan nilai rata-rata biomassa daun-ranting kayu putih pada berbagai ukuran petak ukur, tidak berbeda nyata (Tabel 5). Petak ukur dengan ukuran $20 \times 20$ m dapat menduga biomasa daun-ranting kayu putih yang tidak berbeda dengan ukuran petak ukur 100 x 100 m (1 ha). Dengan ukuran petak ukur yang lebih kecil namun mampu menduga biomasa yang tidak berbeda nyata dengan ukuran 1 ha, waktu dan tenaga untuk membuat petak ukur dan mengukur biomasa daun kayu putih menjadi lebih cepat. Utomo (2012) menyatakan bahwa semakin besar petak ukur dapat menampung keragaman parameter yang diwakilinya namun akan membutuhkan waktu dan biaya yang besar serta pembuatan dan pengukurannya semakin lama.

Tabel 5. Uji t-student berpasangan biomassa daun-ranting kayu putih untuk setiap ukuran petak ukur

Table 5. Pair t-student test for biomass of leave-twigs of cajuput

\begin{tabular}{|c|c|c|c|c|}
\hline \multirow{2}{*}{$\begin{array}{l}\text { Luas petak ukur }\left(\mathrm{m}^{2}\right) \\
(\text { plot size })\left(\mathrm{m}^{2}\right)\end{array}$} & \multirow{2}{*}{$\mathbf{t}_{\text {hitung }}$} & \multicolumn{2}{|c|}{$t_{\text {tabel }}$} & \multirow{2}{*}{$\begin{array}{c}\text { Kecermatan }(\%) \\
\text { (precision) }(\%)\end{array}$} \\
\hline & & 0,05 & $\mathbf{0 , 0 1}$ & \\
\hline $20 \times 20$ & 0,75637 & 2,306 & 3,355 & 1,774 \\
\hline $30 \times 30$ & 0,76726 & 2,306 & 3,355 & 1,330 \\
\hline $40 \times 40$ & 0,82256 & 2,306 & 3,355 & 1,019 \\
\hline $50 \times 50$ & 1,14404 & 2,306 & 3,355 & 0,786 \\
\hline $60 \times 60$ & 0,52475 & 2,306 & 3,355 & 0,763 \\
\hline $70 \times 70$ & 0,47799 & 2,306 & 3,355 & 0,765 \\
\hline $80 \times 80$ & 0,08438 & 2,306 & 3,355 & 0,736 \\
\hline $90 \times 90$ & $-0,48366$ & 2,306 & 3,355 & 0,684 \\
\hline
\end{tabular}

Keterangan : Data diolah dari data primer

Remarks : Data processed from primary data primer 
Luas petak ukur optimal di lokasi penelitian dalam menaksir jumlah pohon dan biomassa daun-ranting kayu putih diperoleh pada ukuran $20 \times 20 \mathrm{~m}$. Nilai tersebut tidak jauh berbeda dengan hasil penelitian Utomo (2012) di hutan tanaman kayu putih Perhutani, untuk plot ukur yang digunakan dalam menyusun model produksi kayu putih adalah 25 x $25 \mathrm{~m}$.

Petak ukur dalam penelitian di hutan tanaman kayu putih menggunakan ukuran 20 x $20 \mathrm{~m}$. Penelitian Budiadi, Ishii, Sigit, \& Yoichi (2005) mengenai variasi kualitas minyak kayu putih dalam berbagai sistem agroforestry juga menggunakan petak ukur 20 x 20 m. Selain itu, petak ukur 20 × $20 \mathrm{~m}$ juga dilakukan oleh Budiadi et al., (2005) untuk meneliti biomasa tanaman kayu putih di berbagai sistem agroforestry di Jawa, Siarudin et al., (2013) untuk menduga potensi daun kayu putih di Taman Nasional Wasur.

\section{KESIMPULAN DAN SARAN}

\section{A. Kesimpulan}

Luas petak ukur optimal untuk menduga jumlah pohon dan biomasa daun kayu putih di lokasi penelitian adalah 20 x $20 \mathrm{~m}$. Dengan luas petak ukur tersebut, kecermatan sampling yang dihasilkan juga sangat baik.

\section{B. Saran}

Hasil penelitian dapat dijadikan bahan pertimbangan KPH Yogyakarta dalam pelaksanaan inventarisasi tanaman kayu putih untuk menduga jumlah tanaman dan biomasa daun kayu putih. Penelitian selanjutnya dapat diterapkan pada lokasi hutan tanaman kayu putih dengan kerapatan tegakan yang berbeda-beda.

\section{UCAPAN TERIMA KASIH}

Penulis mengucapkan terima kasih kepada KPH Yogyakarta, dosen di Departemen Manajemen Hutan Fakultas Kehutanan Universitas Gadjah Mada, reviewer yang telah memberikan masukan konstruktif, dan semua pihak yang telah memberikan dukungan dalam penelitian.

\section{DAFTAR PUSTAKA}

Badan Penelitian Pengembangan dan Inovasi Kementerian Lingkungan Hidup dan Kehutanan. (2016). Benih Unggul Kayu Putih Dikembangkan di NTB. Diakses 18 Januari 2018 dari http://www.forda- mof.org/berita/post/ 2663

Badan Pusat Statistik. (2016). Statistik Produksi Kehutanan 2015. Jakarta: Badan Pusat Statistik.

Baskorowati, L., Susanto, M., Prastyono, Kartikawati, N., \& Rimbawanto, A. (2012). Variation Of Seed Production And Viability In A Full-Sib Trial Of Melaleuca cajuputi sub sp. cajuputi in Gunungkidul Yogyakarta. Journal of Forestry Research 9(2): 73-80.

Budiadi, Ishii, H. T., Sigit, S., \& Yoichi, K. (2005). Variation in Kayu Putih (Melaleuca leucadendron LINN ) Oil Quality under Different Farming Systems in Java , Indonesia. Eurasian Journal Forest Resources 8(1): 15-20.

Budiadi, Kanazawa, Y., Ishii, H. T., Sabarnurdin, M. S., \& Suryanto, P. (2005). Productivity of Kayu Putih (Melaleuca leucadendron LINN) Tree Plantation Managed In Non-Timber Forest Production Systems in Java, Indonesia. Agroforestry Systems 64(2): 143-155.

Dinas Kehutanan dan Perkebunan DIY. 
(2014). Rencana Pengelolan Hutan Jangka Panjang Kesatuan Pengelolaan Hutan Produksi (RPHJP KPHP) Model Yogyakarta Daerah Istimewa Yogyakarta. Dinas Kehutanan dan Perkebunan DIY. Harbagung, \& Imanuddin, R. (2009). Penentuan Ukuran Optimal Petak Ukur Permanen Untuk Hutan Tanaman Jati (Tectona grandis Linn.f). Jurnal Penelitian Hutan Dan Konservasi Alam 6(1): 57-68.

Kementerian Kehutanan. (2012). Statistik Kehutanan Indonesia 2011. Kementerian Kehutanan Republik Indonesia.

Kodir, A., Hartono, D., Haeruman, H., \& Mansur, I. (2017). Integrated Post Mining Landscape For Sustainable Land Use; A case study in South Sumatera, Indonesia. Sustainable Environment Research 27: 203-213.

Perhutani. (2012). Laporan Tahunan Perhutani Tahun 2012. Perhutani.

Sadono, R., Murdawa, B., Soeprijadi, D., \& Nawari. (2016). Biometrika Hutan. Interlude.

Salaka, F. J., Nugroho, B., \& Nurrochmat, D. R. (2012). Strategi Kebijakan Pemasaran Hasil Hutan Bukan Kayu di Kabupaten Seram Bagian Barat. Jurnal Analisis Kebijakan Kehutanan 9(1): 50-65.

Siarudin, M., Winara, A., Indrajaya, Y., Junaidi, E., \& Widiyanto, A. (2013). Potensi Produksi Daun dan Minyak Kayu Putih Jenis Asteromyrtus symphyocarpa di Taman Nasional Wasur. Jurnal Hutan Tropis 1(3): 236-241.

Simon, H. (2010). Perencanaan Pembangunan Sumber Daya Hutan jilid I.A Timber Management. Pustaka Pelajar.

Utomo, P. M. (2012). Model Produksi Daun Pada Hutan Tanaman Kayu Putih (Melaleuca cajuputi Subsp cajuputi Powell). (Disertasi Doktor). Institut Pertanian Bogor, Bogor.

Utomo, P. M., Suhendang, E., Syafii, W., \& Simangunsong, B. C. (2012). Model Produksi Daun Pada Hutan Tanaman Kayu Putih (Melaleuca cajuputi Subsp cajuputi. Powell) Sistem Pemanenan Pangkas Tunas. Jurnal Hutan Tanaman, 9(4): 195-208.

Vanclay, J. K. (1994). Modelling forest growth and yield: applications to mixed tropical forests. Modelling forest growth and yield: applications to mixed tropical forests. CAB International. 